\title{
Clinically Complete Recovery after Bilateral Paramedian Thalamic Infarction
}

\section{Klinik Olarak Tamamen Düzelen Bilateral Paramedyan Talamik İnfarkt}

Keywords: Bilateral, paramedian thalamic infarct, atrial fibrillation, recovery

Anahtar Kelimeler: Bilateral, paramedyan talamik infarkt, atrial fibrilasyon, iyileşme

\section{Dear Editor,}

A 61-year-old woman presented to the emergency department with a reduced level of consciousness. On arrival, her Glasgow Coma scale (GCS) was 6/15 (eye: 1, verbal: 1, motor: 4). On physical examination, the patient grimaced to painful stimuli and plantar reflexes were positive bilaterally. The pupils were unequal and mydriatic, both unresponsive to light. Her blood pressure was $180 / 120 \mathrm{mmHg}$ and blood glucose level, body temperature, heart rate, and respiratory rate were within normal limits. The National Institutes of Health Stroke Scale (NIHSS) score was 25. Cardiovascular and respiratory examinations were normal. There were no signs of hemorrhage in brain computed tomography (CT). Diffusion-weighted magnetic resonance imaging (MRI) showed bilateral paramedian thalamic infarction (Figure 1A, 1B).

The patient was intubated and admitted to the intensive care unit. She was started on $300 \mathrm{mg} /$ day acetylsalicylic acid for ischemic stroke. Additionally, amantadine $200 \mathrm{mg} /$ day was started to increase wakefulness. Due to the high NIHSS score, the lack of information regarding the exact time when the event started, and the high risk of hemorrhage, thrombolytic therapy was not considered. The patient was extubated after 48 hours. On the second physical examination, the right pupil was mydriatic and unresponsive and there was vertical gaze palsy and skew deviation in the same eye. Muscle strength of the four extremities was 5/5, bilateral plantar reflex was positive, and GCS was 13 (E3, V4, M6). After five days from hospitalization, the GCS was 15 and a neurologic examination was normal. A crain CT scan and carotid-vertebral angiogram excluded any major intracranial artery occlusion (Figure 2). A 24-h Holter monitor showed paroxysmal atrial fibrillation; therefore, warfarin therapy was started.

Bilateral thalamic infarction is rare, representing $0.6 \%$ of all ischemic strokes, with paramedian thalamic infarction being the most common subtype (75\%) (1). The etiology of vertebrobasilar ischemia remains controversial. Recent studies have demonstrated that cardiac embolism is responsible for about one-fifth of the cases of brain embolism that manifest with the signs and symptoms of vertebrobasilar insufficiency (2). In our patient, the a Holter monitor showed paroxysmal atrial fibrillation that could cause
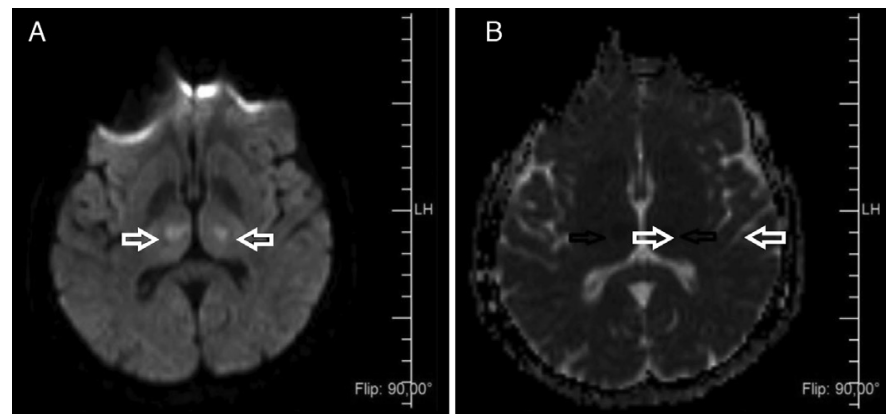

Figure 1. A) Diffusion-weighted axial image showing hyperintense signal in bilateral paramedian thalami in the areas of infarction consistent with infarction (arrows), B) Axial apparent diffusion coefficient map showing decreased signal in bilateral thalami in the areas of infarction (arrows)

\footnotetext{
Address for Correspondence/Yazışma Adresi: İrem Taşcı MD, Malatya Training and Research Hospital, Clinic of Neurology, Malatya, Turkey Phone: +905369550534 E-mail: tasciiirem@gmail.com ORCID ID: orcid.org/0000-0001-7069-769X Received/Geliş Tarihi: 05.04.2018 Accepted/Kabul Tarihi: 02.09.2018

${ }^{\circ}$ Copyright 2018 by Turkish Neurological Society

Turkish Journal of Neurology published by Galenos Publishing House
} 


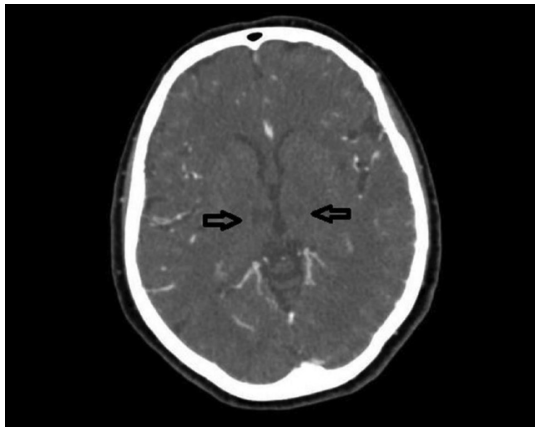

Figure 2. Brain computed tomography angiography performed five days after hospitalization showing hypodensities in bilateral paramedian thalami in the areas of infarction (arrows)

systemic embolism and no stenotic lesion was observed on cerebral and carotid-vertebral CT angiography.

Typical symptoms of bilateral paramedian thalamic infarction include vertical gaze palsy, memory impairment, akinetic mutism, confusion, drowsiness, hypersomnolence, and coma (3). Literature reviews indicate that there are very few cases of bilateral paramedian thalamic infarction that show complete recovery. The first case was reported by Krolak-Salmon et al. (4) in 2000 and the second case was a 41 -year-old male patient who recovered within 3 hours, reported by Khoiny et al. (5) in 2006. Another case was presented by Viticchi et al. (6), a 35-year-old pregnant woman in whom brain MRI showed a symmetrical bilateral paramedian thalamic infarction. The patient showed full clinical recovery within a few hours after the onset of the symptoms. Our patient also showed complete recovery with no sequelae within a few days.

In conclusion, in patients with coma and normal metabolic, respiratory, and cardiac parameters, cerebrovascular disease affecting the thalamus should be considered. In our patient, neurovascular imaging revealed no vascular pathology and atrial fibrillation was the only etiology. Moreover, it is a rare case of complete recovery. For this reason, it may attract attention.

\section{Ethics}

Informed Consent: Consent form was filled out by all participants.

Peer-review: Internally peer-reviewed.

\section{Authorship Contributions}

Surgical and Medical Practices: İ.T., Concept: C.F.D., Design: C.F.D., Data Collection or Processing: M.B., Analysis or Interpretation: İ.T., Literature Search: M.B., Writing: İ.T.

Conflict of Interest: No conflict of interest was declared by the authors.

Financial Disclosure: The authors declared that this study received no financial support.

\section{References}

1. Kumral E, Evyapan D, Bakır K, Kutluhan S. Bilateral thalamic infarction: Clinical, etiological and MRI correlates. Acta Neurol Scand 2001;103:35-42.

2. Caplan LR. Brain embolism revisited. Neurology 1993;43:1281-1287.

3. Lazzaro NA, Wright B, Castillo M, et al. Artery of percheron infarction: imaging patterns and clinical spectrum. Am J Neuroradiol 2010;31:1283-1289.

4. Krolak-Salmon P, Croisile B, Houzard C, Setiey A, Girard-Madoux P, Vighetto A. Total recovery after bilateral paramedian thalamic infarct. Eur Neurology 2000;44;216-218.

5. Khoiny A, Golberg M, Khoiny N. Atypical Presentation with Good Outcome in a Bilateral Paramedian Thalamic Infarction. Journal of Neurological Science 2006;23:1

6. Viticchi G, Falsetti L, Fiori C, et al. Acute Occlusion of the Percheron Artery during Pregnancy: A Case Report and a Review of the Literature. J Stroke Cerebrovasc Dis 2016;25:572-577. 